\title{
Knowledge exchange systems for youth health and chronic disease prevention: a tri-provincial case study
}

\author{
D. Murnaghan, PhD (1); W. Morrison, PhD (2); E. J. Griffith, PhD (3, 4); B. L. Bell, PhD (1); L. A. Duffley, BSc (2); \\ K. McGarry, MSc (3); S. Manske, PhD (5)
}

This article has been peer reviewed.

\begin{abstract}
Introduction: The research teams undertook a case study design using a common analytical framework to investigate three provincial (Prince Edward Island, New Brunswick and Manitoba) knowledge exchange systems. These three knowledge exchange systems seek to generate and enhance the use of evidence in policy development, program planning and evaluation to improve youth health and chronic disease prevention.
\end{abstract}

Methods: We applied a case study design to explore the lessons learned, that is, key conditions or processes contributing to the development of knowledge exchange capacity, using a multi-data collection method to gain an in-depth understanding. Data management, synthesis and analysis activities were concurrent, iterative and ongoing. The lessons learned were organized into seven "clusters."

Results: Key findings demonstrated that knowledge exchange is a complex process requiring champions, collaborative partnerships, regional readiness and the adaptation of knowledge exchange to diverse stakeholders.

Discussion: Overall, knowledge exchange systems can increase the capacity to exchange and use evidence by moving beyond collecting and reporting data. Areas of influence included development of new partnerships, expanded knowledge-sharing activities, and refinement of policy and practice approaches related to youth health and chronic disease prevention.

Keywords: knowledge exchange, youth health, chronic disease prevention, knowledge use, evidence to action, surveillance, partnerships

\section{Introduction}

The burden of chronic disease is increasing worldwide, and chronic disease accounts for $89 \%$ of deaths in Canada. ${ }^{1}$ Canadian youth are at risk of developing chronic diseases due to their high rates of modifiable harmful health behaviours such as physical inactivity, ${ }^{2,3}$ unhealthy eating ${ }^{4}$ and tobacco use $\mathrm{e}^{5}$ and may have shorter life expectancies than their parents as a result. ${ }^{4}$ The greatest leverage of risk reduction might be achieved through timely intervention early in life. ${ }^{6}$

With these increasing rates of chronic disease, we need to urgently generate and use relevant evidence to inform and guide effective youth health policies and programs. Evidence-based planning enhances prevention programs ${ }^{7,8}$ by targeting and evaluating programs and policies and setting priorities. ${ }^{9}$ As a result, locally relevant and contextual data on modifiable risk factors are in demand.

Various terms, including "knowledge exchange," "knowledge translation" and "knowledge development" refer to the process of undertaking research with the intention of effectively applying the resultant data. According to the Canadian Health Services Research Foundation, knowledge exchange (KE) emphasizes the two-way interaction between groups with separate and distinct cultures to ensure that the knowledge created is both useful and relevant to all stakeholders. ${ }^{10,11}$ This definition fits with the philosophical approach and the proposed interventions of this study.

Several existing KE frameworks identify the key processes, people and contextual conditions necessary to develop knowledge and act on it. Jacobson et al. ${ }^{12}$ provided a practical guide to KE to assist researchers in gathering relevant information about the critical target groups for KE. The Canadian Institutes of Health Research conceptualizes knowledge translation as a dynamic and iterative process that includes synthesis, dissemination, exchange and ethically sound application of knowledge as well as evaluation and monitoring of knowledge translation activities. ${ }^{13}$ A third framework is the knowledge-to-action research framework, which is composed of two fluid, complex

\section{Author references:}

1. Faculty of Nursing, University of Prince Edward Island, Charlottetown, Prince Edward Island, Canada

2. Faculty of Education, University of New Brunswick, Fredericton, New Brunswick, Canada

3. Epidemiology and Cancer Registry, CancerCare Manitoba, Winnipeg, Manitoba, Canada

4. Department of Community Health Sciences, Faculty of Medicine, University of Manitoba, Winnipeg, Manitoba, Canada

5. Propel Centre for Population Health Impact, University of Waterloo, Waterloo, Ontario, Canada

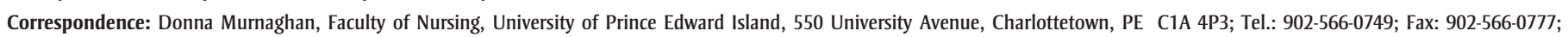
Email: dmurnaghan@upei.ca 
and dynamic cycles: knowledge creation and action. ${ }^{11}$

Although KE has long been recognized as a key to translating knowledge into action, the research to inform and support such efforts is still being developed. Within Canada, stakeholders from policy, practice and research sectors of provincial and national health promotion and chronic disease organizations agree on the importance of better understanding KE processes and examples of evidence-informed practice in local, regional and provincial contexts. They also recognize the need for systems thinking in public health as an emerging method to address complex public health issues. ${ }^{14}$

Building on existing frameworks, three provinces have independently created their own provincial youth health KE systems: Prince Edward Island's School Health Action, Planning, and Evaluation System Prince Edward Island (SHAPES-PEI; http://www.upei.ca/cshr/shapes); New Brunswick's Student Wellness Survey and
Knowledge Exchange Initiative (SWS/KE; http://www.unbf.ca/education/herg/ wellness/index.php); and Manitoba's Risk Factor Surveillance System (MRFSS; http://partners.healthincommon.ca). Each of the three provinces established a knowledge-to-action process that recognizes the value of providing evidence-to-inform actions and learning from action-to-refine evidence (see Figures 1, 2 and 3). Four core components of youth health $\mathrm{KE}$ were identified in the three provincial $\mathrm{KE}$ frameworks:

(1) Surveillance systems to support planning and evaluating of policies and programs for children and youth (i.e. collecting local data including risk factor data);

(2) The ability to synthesize relevant evidence with respect to the kinds of interventions that prove to be effective (i.e. interpretation of data informed by literature, program evaluations and the local context);

(3) The capacity to move evidence into action (i.e. using the knowledge derived from interpreting data to implement better practices); and

(4) The means of generating evidence from action (i.e. learning from and sharing better practices, programs, policies, interventions, experiences and evaluations).

The purpose of this paper is to present the lessons learned from this tri-provincial case study of KE systems for youth health and chronic disease prevention.

\section{Methods}

We used the Yin $^{15}$ case study design to explore the phenomena of youth health KE across three diverse provinces: Manitoba, New Brunswick and Prince Edward Island. Case study design is useful for answering how and why questions whereas multiple case design can be used to explore differences between and within cases and to predict similar results or to predict contrasting results, but for foreseeable reasons. ${ }^{15}$ For this study, we used a multi-data collection method to gain an

FIGURE 1

\section{SHAPES-PEI Knowledge Development and Exchange Model}

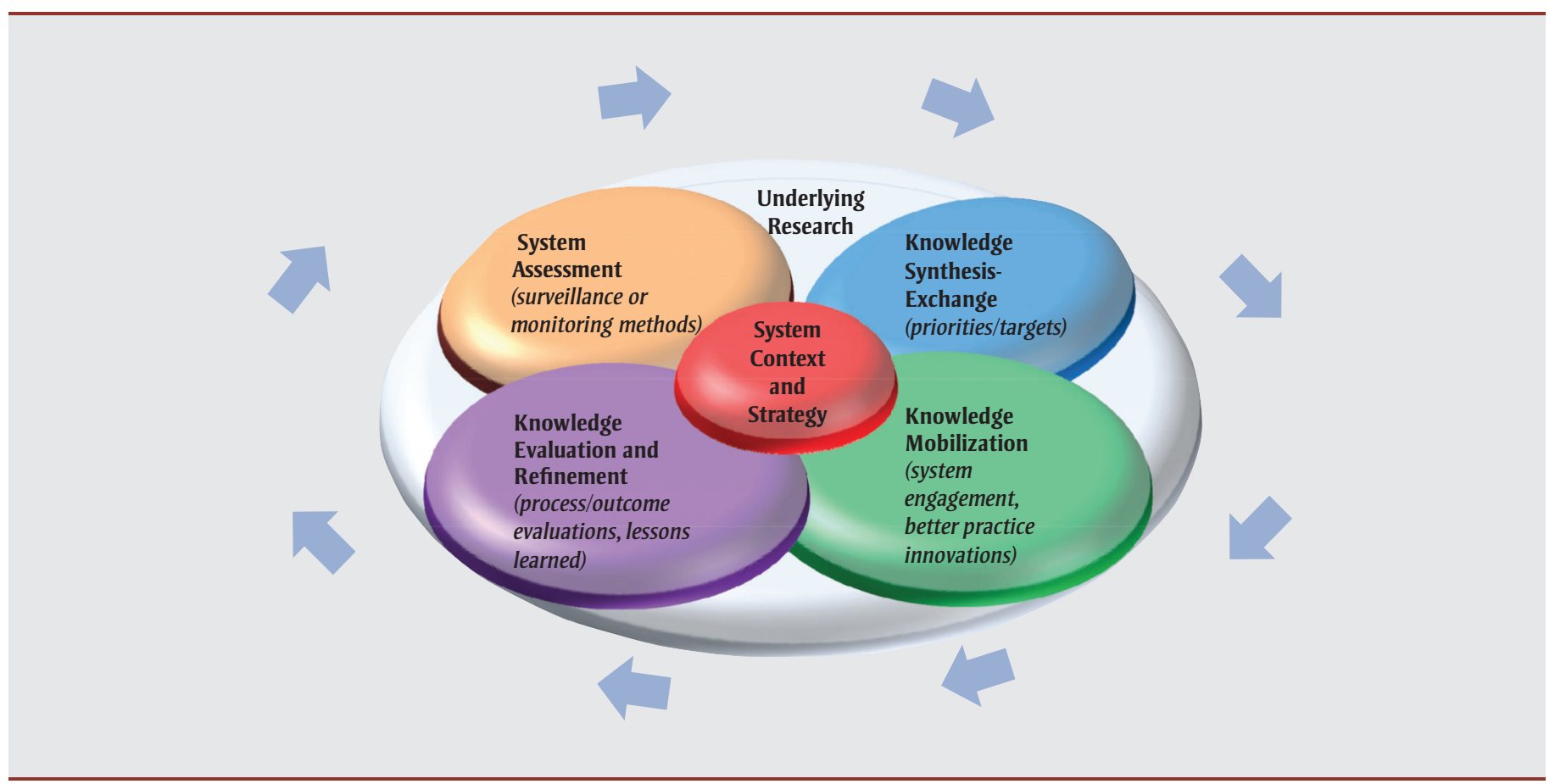

Abbreviation: SHAPES-PEI, School Health Action, Planning and Evaluation System - Prince Edward Island.

Note: Figure developed by partners from across Canada including Propel Centre for Population Health Impact (University of Waterloo, Waterloo, Ontario, Canada) and the Health and Education Research Group (University of New Brunswick, Fredericton, New Brunswick, Canada). 
FIGURE 2

YEAR 1

Research Planning

(Literature Review, Ethics, Surveillance

Measures, etc.)

Data Collection, Analysis \& Synthesis

Knowledge Products Development

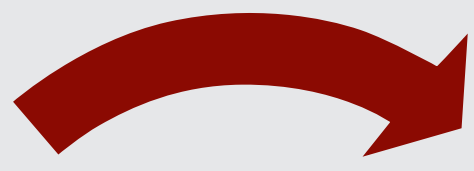

\section{YEAR 2}

Knowledge Translation

Knowledge Products Distribution

Translation \& Application

Strategic Planning \& Priority Setting

Process Evaluation

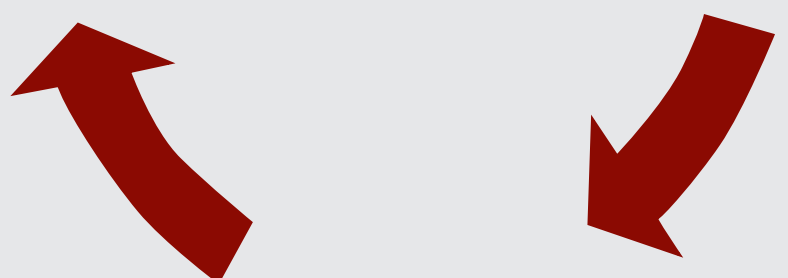

YEAR 3

Knowledge Mobilization

Better Practice \& Lessons Learned Sharing

Adoption \& Implementation

Strategic Refinement \& Integration

Process/Outcome Evaluation

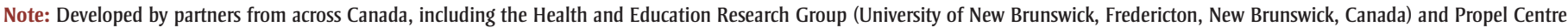
for Population Health Impact (University of Waterloo, Waterloo, Ontario, Canada).

in-depth understanding of $\mathrm{KE}$ within the real life context of youth health. ${ }^{15}$

\section{Procedures}

Each provincial case study developed a research team and advisory committees for this initiative. In addition, the three provinces formed a multi-site research team that consisted of the principle investigators and research staff from each province. While study protocols provided focus and direction, each provincial research team had the autonomy to explore their cases using methods best suited to their context. The teams collaborated to refine processes and instruments for data collection. The many sources of evidence (document analyses, interviews, focus groups and an online survey in Prince Edward Island) enhanced the reliability and validity of case study results (see Table 1 ). ${ }^{15}$

Collaborating with provincial and national stakeholders, the research teams developed semi-structured interview guides (available on request). Interviews and focus groups were tape-recorded and the recordings transcribed; field notes were also constructed immediately following each interview. ${ }^{16}$ Interviews lasted about 45 to 60 minutes. A structured online survey in Prince Edward Island, used to understand the viewpoints of a larger spectrum of partners, end-users and stakeholders, took about 10 to 15 minutes to complete. The documents reviewed included planning and resource documents, meeting minutes, grant applications, communications and press clippings. Data were collected until saturation, (when identified themes became repetitive) was achieved within each provincial case.

We took steps to prevent interviewers leading or influencing participants by sharing opinions, etc. ${ }^{17}$ We used member-checking to reach saturation, to make sure that we thoroughly understood emerging themes and that our findings reflected participants' contributions, and to clarify and explore details of participants' initial interviews. About six months after the initial interviews and focus groups, and after preliminary analyses were completed and themes identified, we shared the initial findings with participants; however, only half were able to participate in follow-up interviews.

The appropriate research ethics board(s) in each province gave ethical approval for the research.

\section{Participants}

We used purposeful sampling to identify participants in existing KE networks. This was followed by snowball sampling to reach key stakeholders. All participants were told about the project by email and/or in person and provided informed consent prior to participation. Participants included representatives of provincial health/wellness and education government departments; non-governmental organizations; regional health authorities; schools and school districts; universities; and other key stakeholders who were involved directly in the KE system in their 
FIGURE 3

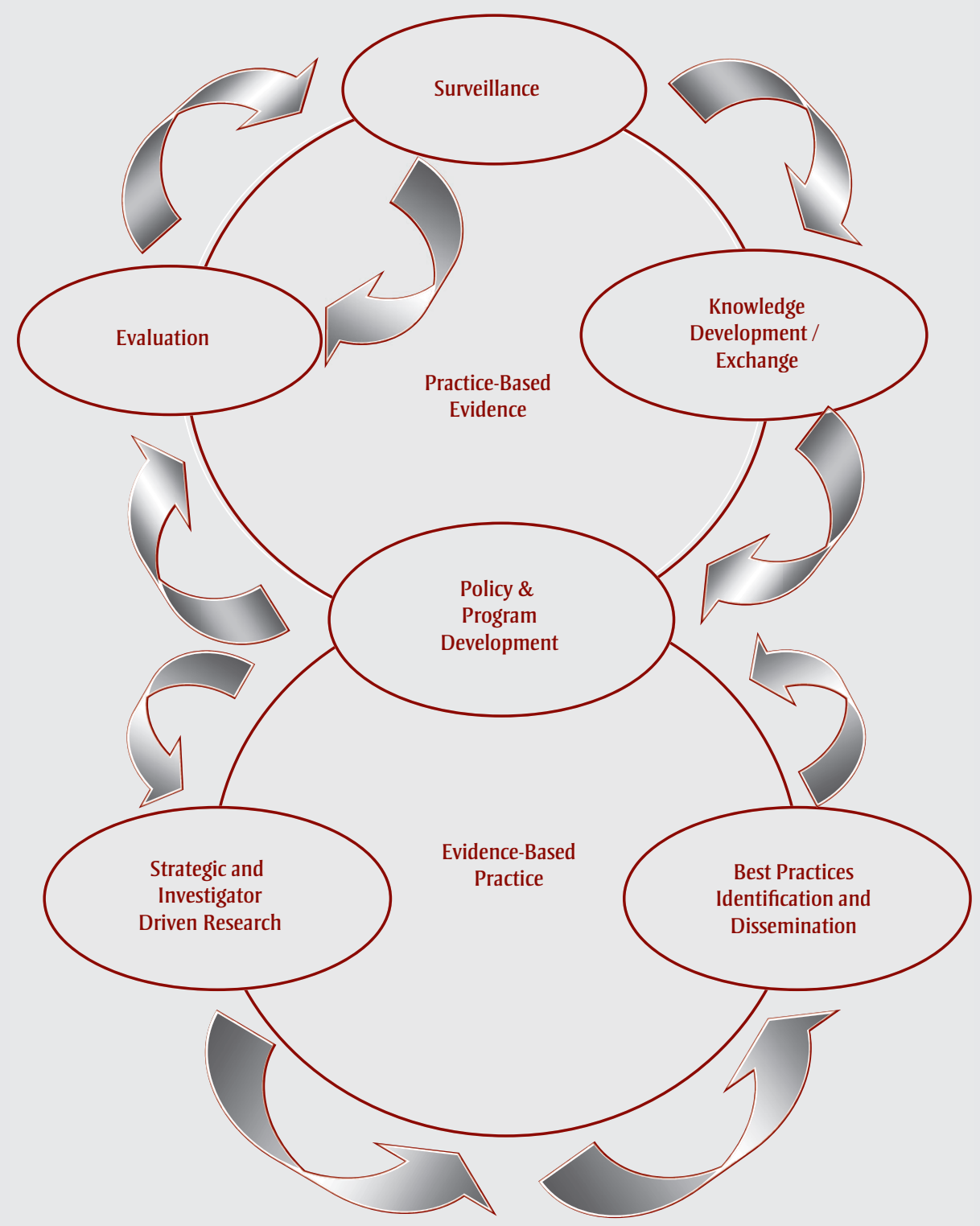

Source: Riley and Harvey, 2006. ${ }^{18}$

province as either partners and/or endusers (see Table 2). Fewer than ten participants from any one province declined participation in the study.

\section{Data analysis}

Data management, synthesis and analysis activities were concurrent, iterative and ongoing. We used NVivo 8/9 software
(QSR International (Americas) Inc., Burlington, MA, US) to manage and analyze data. Analysis focused on thematic surveys and conceptual/thematic description. ${ }^{17}$ Each provincial team used thematic analysis to examine, categorize and tabulate data from multiple sources. Themes were used to label and order portions of the data, and interpretative analysis was used to understand the meaning of the themes. ${ }^{19}$
Findings were cross-checked between provincial final reports, participants, document reviews and cross-case discussions.

The provincial teams agreed to use a modified multiple case study analysis procedure as described by Stake. ${ }^{20}$ An initial framework was built upon a priori themes identified in the literature and emergent themes resulting from each 
TABLE 1

Summary of data collection activities

\begin{tabular}{lcccc} 
& Documents, $\mathbf{n}$ & Interviews, ${ }^{\text {a }} \mathbf{n}$ & Survey Respondents, $\mathbf{n}$ & $\begin{array}{c}\text { Focus Groups, } \mathbf{n} \\
\text { (Participants, } \mathbf{n} \text { ) }\end{array}$ \\
\hline MB & 137 & 32 & 0 & $6(35)$ \\
NB & 78 & 32 & 0 & $2(48)$ \\
PEI & 119 & 26 & 69 & $7(50)$ \\
\hline
\end{tabular}

Abbreviations: MB, Manitoba; NB, New Brunswick; PEI, Prince Edward Island.

${ }^{\text {a }}$ Total number of interviews conducted (some individuals may have participated in multiple data collection activities).

provincial case and cross-province discussion. Findings were sorted into the framework's identified “clusters." Next, an intensive iterative process across the provincial case study teams resulted in identifying patterns from which emerged a final framework (see Table 3). Common strategies, partners and activities that lead to increased KE uptake could be examined within the framework.

The results of this cross-case study focus on similarities between KE systems, but we also looked for counter-evidence to avoid holistic bias and to make sure that we did not assume greater meaning in the patterns than actually existed. ${ }^{17}$ Examining counterevidence along with supporting evidence resulted in modifications to and/or support for the emerging framework. Focusing on similarities allowed for the emergence of key elements, processes and lessons learned in implementing a KE system. This mutually inductive and deductive process served to deepen critical reflection and to identify the potential range of impact of emerging lessons from each provincial case.

\section{Results}

The diverse context (social, political, physical) of each provincial KE system has led to different partnership, funding and structure models. Nevertheless, our cross-case comparison identified similarities between the three provincial KE systems that we expressed as lessons learned within seven “clusters.” Lessons learned are defined as key conditions or processes contributing to the development of KE capacity across at least two provincial contexts. Select quotes from research participants are included to demonstrate support for our lessons learned. We purposefully did not identify the provinces where a particular interview took place to preserve the anonymity of all research participants.

\section{Guiding knowledge exchange models}

All three provinces used existing system frameworks with key processes, people and contextual conditions as a foundation for their surveillance initiatives to plan and execute activities and to guide and
TABLE 2

Interview and focus group participant descriptives

\begin{tabular}{lccc} 
Interviews & PEI $(\mathbf{n}=\mathbf{2 3})$ & NB $(\mathbf{n}=\mathbf{3 2})$ & MB $(\mathbf{n}=\mathbf{3 2})$ \\
\hline Roles, \% & & & 0 \\
Research & 26 & 16 & 16 \\
Policy & 26 & 19 & 84 \\
Practice & 39 & 65 & 0 \\
Other & 9 & 0 & MB $(\mathbf{n}=35)$ \\
\hline Focus Groups & PEI $(\mathbf{n}=\mathbf{5 0})$ & NB $(\mathbf{n}=48)$ & 0 \\
\hline Roles, \% & & & 9 \\
Research & 0 & 8 & 91 \\
Policy & 0 & 15 & 0 \\
Practice & 0 & 77 & 0 \\
Student & 100 & & \\
\hline
\end{tabular}

Abbreviations: MB, Manitoba; NB, New Brunswick; PEI, Prince Edward Island. communicate the ongoing work. Although these models were different in each province, using KE models helped to communicate and understand different stakeholders' roles in developing, sharing or applying knowledge. Two interviewees explained:

I think for [the student survey] to be really successful, the participants, whether they are the principals or the parents or the kids ... need to get a sense of what is next and understand that this is going to inform the next step and this is the timeline to the next step so that everybody knows that this is the start of a process versus the end of a process. (Province 1)

It is critical to have a road map and to prioritize as part of the way we do our business. (Province 2)

\section{State of readiness}

All provinces acknowledged a need for health-related data to inform policy or practice development, and health/wellness and education stakeholders expressed an interest in establishing youth health $\mathrm{KE}$ activities.

Some schools are ready to rock-and-roll with this sort of stuff; other schools are just [on] the cusp of getting involved. (Province 1)

All three provinces lacked comprehensive local level data related to youth health behaviours. Existing networks, coalitions and working relationships were critical to providing an initial foundation for promoting the value of youth health surveillance and KE to inform policy development and practices. Champions who promoted and facilitated the development of surveillance and KE processes came from a variety of stakeholder groups.

We have a very diverse region. We have affluent, healthy ... population[s and] areas [with] high rates of chronic disease. [A] regional average puts it somewhere in the middle. So having the school data would really help 
TABLE 3

Cross-case comparison analytical framework

\begin{tabular}{|c|c|c|}
\hline & Cluster Name & Cluster Description \\
\hline 1. & Guiding knowledge exchange models & Existing system frameworks that identified key processes, people and contextual conditions \\
\hline 2. & State of readiness & $\begin{array}{l}\text { An acknowledged need for health-related data to inform policy or practice development at either local, } \\
\text { provincial or national levels and expressed interest from health/wellness and education stakeholders }\end{array}$ \\
\hline 3. & Knowledge exchange products & $\begin{array}{l}\text { Communication resources, such as reports, facts sheets, websites, etc., intended to engage and inform } \\
\text { multiple audiences }\end{array}$ \\
\hline 4. & Knowledge exchange activities & Events, forums, meetings, presentations or planning sessions designed to engage stakeholders \\
\hline 5. & Strategic partnerships in knowledge exchange & Specific relationships or collaborations identified as playing a key leadership or influential role \\
\hline 6. & Systems and structures & Established or emerging knowledge exchange networks or decision-making systems \\
\hline 7. & Knowledge exchange impacts & $\begin{array}{l}\text { Concrete ways in which surveillance outcomes or knowledge exchange activities have contributed to } \\
\text { embedding or linking knowledge-to-action processes within existing or emerging planning and decision- } \\
\text { making systems }\end{array}$ \\
\hline
\end{tabular}

Abbreviation: KE, knowledge exchange.

determine what programs need to go in what communities. (Province 3)

\section{Knowledge exchange products}

KE products, for example, communications resources such as reports, facts sheets, websites, newsletters, project summaries, conference proceedings, and media communications used to engage and inform multiple audiences provided a common entry point for all three provinces to initiate dialogues with existing and new stakeholders. They were used to present comprehensive findings on youth health behaviours that affect chronic disease such as healthy eating, physical activity, tobacco use and mental fitness. A variety of $\mathrm{KE}$ products, written in familiar and simple language, were designed for specific audiences and stakeholder groups (see Table 4). Concise summaries or fact sheets highlighting key youth health outcomes were identified as appealing and interesting to senior policy makers and leaders. Websites were used to make youth health data and resources for $\mathrm{KE}$ accessible to a wider range of stakeholders.

I found [the profile report] easy to go through, easy to read, from my perspective. I mean, I know some parents may be challenged to go through it, but I liked the format ... here is the data; this is what it means; this is the action that you could take. (Province 1)

The website is fantastic. For isolated communities it's the most beneficial. My team goes there for resources quite a bit. (Province 3)

\section{Knowledge exchange activities}

Focusing on exchanging information with stakeholders at all levels was important in each province; creating engaging KE activities-events, forums, meetings, presentations or planning sessions-was considered essential. KE activities were planned and implemented based on strategic processes within each respective provincial KE model.

TABLE 4

Knowledge exchange products

\begin{tabular}{ll} 
Product & \multicolumn{1}{c}{ Intended Audience } \\
\hline School reports / summary reports & $\begin{array}{l}\text { School administrators, teachers, students, parents, school and } \\
\text { community committees }\end{array}$ \\
District/division reports / summary reports & $\begin{array}{l}\text { School district/division staff, school boards, communities, } \\
\text { health practitioners }\end{array}$ \\
Regional reports & $\begin{array}{l}\text { Health practitioners, municipal leaders } \\
\text { Provincial reports / summary reports }\end{array}$ \\
& $\begin{array}{l}\text { Provincial government departments, health alliances, non- } \\
\text { governmental organizations, general public }\end{array}$ \\
\hline
\end{tabular}

Regional and provincial KE champions were often identified as co-ordinators, hosts and/ or presenters at KE activities. KE activities were identified as beneficial for bringing together stakeholders and facilitating the development of partnerships.

It is these sharing and exchanging opportunities that provide us with new networks, ideas and successes ... this keeps us motivated. (Province 2)

We presented the information from the reports and had discussions around what does this mean to you [sic]. It gave them an opportunity to ask questions and for us to clarify. (Province 3)

\section{Strategic partnerships in knowledge exchange}

Leadership and established collaborations between stakeholders with expertise in youth health/wellness, education and research were identified as critical for supporting and maintaining surveillance initiatives. Developing partnerships within the education sector was necessary for obtaining and sustaining the participation of schools and districts.

Truthfully, we had spent a lot of years really ensuring we had built those relationships, that we had made the calls. We had meetings with them on a regular basis. We asked, "What are we doing right? What are we doing wrong? How can we make this better?" So we did work hard at that. (Province 1) 
In our small province, it is the practitioners that enable us to accomplish so much with limited resources ... Partnerships are key to the strength of the initiative. (Province 2)

\section{Systems and structures}

Established or emerging KE networks or decision-making systems were recognized as playing a key role in the development and expansion of KE capacity. Pre-existing national networks provided the initial network structure from which to initiate and foster relationships among research, policy and practice stakeholders. Health coalitions, groups, networks and initiatives made use of youth health surveillance data for program planning and health promotion. Surveillance and KE activities were also identified as supporting the development of youth health/wellness planning committees and structures.

What [the school health network's] role would be to formalize those discussions that we have informally and that probably should be created so when the players change ... those conversations continue in a formalized way. (Province 1)

Members benefit from the unique contributions of all of our partners based on their experiences, resources and expertise. (Province 3)

\section{Knowledge exchangé outputs}

Stakeholders were helped in interpreting and using results so that they could effectively move evidence to action. KE outputs included applying surveillance results, assessing priorities, engaging partners and leveraging funding. Grant programs linked with school health surveillance were associated with increased uptake of KE reports and the use of evidence. Success stories were identified as important sources of motivation and learning. Repetition of the surveillance and KE activities provided an important foundation for building and sustaining school health partnerships. The use of youth health data by departmental stakeholders and/or external groups to set regional and provincial health/wellness plans and priorities as well as to establish program benchmarks was recognized as contributing to widespread support for sustaining school level surveillance and KE activities.

Some of our schools have embedded the information from the [survey] into ongoing school improvement plans. This works in districts too. (Province 2)

I remember getting the results and because there was the healthy living grant we shared it with the student council and asked them what they wanted to use the grants for and asked them to apply. (Province 3 )

\section{Discussion}

In this paper, we describe the lessons learned about the development and implementation of KE systems in three different Canadian provinces. Our findings demonstrate that the three provincial KE systems are similar and that $\mathrm{KE}$ is a complex process that requires champions, collaborative partnerships, readiness and the tailoring of KE to diverse stakeholders. All of these components serve to build capacity and sustain KE systems that lead to the creation of real outcomes promoting healthy living.

Our cross-case study findings contribute to the limited empirical research on KE models. Similar themes emerged across the provinces, including the necessity of utilizing a guiding model of KE when implementing such systems. While each of the three provinces had context-specific approaches, they implemented comparable KE systems as demonstrated through the common analytical framework that emerged.

Several existing frameworks such as the Knowledge-to-Action Process Framework, ${ }^{11}$ Understanding-User Context Framework, ${ }^{12}$ and Model of Knowledge Translation ${ }^{13}$ illustrate specific KE processes designed to bridge the gap between researcher and enduser. Similar to these models, the three provincial KE models focus on including stakeholders in the $\mathrm{KE}$ processes and recognize the role of context in developing, interpreting and applying knowledge. The provincial models reflect many years of effort when knowledge was acted upon in a timely manner by communities mobilized to use evidence in decision making. Repetition allowed for evidence-informed policies and practices to be evaluated and refined. When practices proved ineffective, the systems adapted and incorporated new knowledge gleaned from those systems that applied models in such a way as to effectively use resources and build capacity. As the model was repeated, communication between and collaboration among partners was also extended, elaborated and enhanced.

The analytical KE framework from this study is based on empirical evidence from three different "real life" Canadian jurisdictional experiences, leading to further understanding of KE.

Champions at all levels (local, regional, provincial and national) were essential for eliciting widespread support and advocacy for implementing and continuing surveillance and KE activities. Engaging such networks and champions necessitated promoting the value of evidence-based decision making and the need for collecting and understanding local data. Consistent with the findings of Walter et al., ${ }^{21}$ when these champions endorsed and used youth health data to develop local, regional and provincial health/wellness plans and to establish program benchmarks, the value of local surveillance and KE activities was enhanced among all stakeholders. ${ }^{21}$ Champions act as catalysts by introducing new ideas and practices, endorsing these, ${ }^{21}$ and mentoring others to take action.

Research, policy and practice often have different priorities, use different language, operate on different time scales and are subject to different reward systems. ${ }^{22,23}$ The Centers for Disease Control and Prevention, for example, responded to the need for a common language and conceptualization to expand their understanding of the knowledge-to-action process they were undertaking. ${ }^{24}$ In developing collaborative partnerships, opportunities to increase awareness of work functions and partnership expectations help to create a process of mutual 
understanding that, in turn, leads to mutual respect and collaborative partnerships and actions. KE models and frameworks can serve as important tools in engaging a variety of partners in a systems approach to preventing chronic disease. The use of a KE model helped stakeholders understand, become involved with and sustain their participation in knowledge-to-action activities related to youth health.

Further, positive working partnerships within the education sector were critical for obtaining and sustaining the participation of schools and districts. By maintaining positive relationships through a clearly articulated mutual and respectful process, all partners were welcome to contribute and felt valued. Gagnon ${ }^{25}$ identified four factors for successfully integrating KE within networks and practice communities: the development of shared understanding about the health problem; explicit descriptions of roles/responsibilities; team members with competencies and experience in building and maintaining effective collaborations; and a strategy for ensuring that relationships are maintained. ${ }^{25}$

Key collaborative actions undertaken by the provinces included joint planning of surveillance approaches and their timing, as well as how data will be used and shared across local, regional and provincial jurisdictions. Co-creation of knowledge was found to influence the uptake and use of research by allowing for greater consideration and ability to address contextual factors, thus creating credible and valid information that was both trusted by and useful to stakeholders. ${ }^{26}$ Knowledge that addresses areas of concern and priority for stakeholders increases the likelihood that it will be used or applied. ${ }^{27,28}$ Consistent with our findings, Williams et al. ${ }^{29}$ stressed the importance of involving end-users in all key activities that reflect the knowledge development process. However, examples of sustained, collaborative partnerships and ongoing communication among knowledge producers and end-users are rare and unusual. ${ }^{30}$ Our research demonstrated that repetition of surveillance and KE activities helped sustain the partnerships involved in youth health KE. Partnerships evolved and expanded as partners worked together on common surveillance and KE activities.

The engagement of leaders from various stakeholder groups built the capacity to initiate preliminary actions related to province-wide surveillance and KE activities. Successes with health-related surveillance activities and evidence-to-action planning generated further commitment and support for youth health surveillance from both individuals and organizations, as did deriving evidence from action. Ward et al. ${ }^{31}$ also found that personal, interpersonal, organizational and professional characteristics and context influenced the KE processes, supporting the importance of building upon existing assets such as expertise, partnerships and infrastructure when implementing a KE system. ${ }^{31}$

Collaborative exchanges are facilitated when relevant KE products are accessed and used. Our findings highlighted the importance of tailoring $\mathrm{KE}$ products to diverse stakeholder groups. Appealing features of such products included the use of familiar language and locally relevant information, inclusion of examples of better practices, incorporation of practicebased evidence or success stories, and availability of reports, summaries or fact sheets in multiple formats and locations. KE products such as fact sheets, websites, newsletters, reports, project summaries, conference proceedings, and media communications have promoted collaboration between researchers and research users. $^{24,32} \mathrm{KE}$ products should include suggested actions tailored to further the uptake and use of evidence. ${ }^{33,34}$

A variety of $\mathrm{KE}$ activities are essential to reach and interest diverse stakeholders. These included individual consultations with stakeholders on youth health/wellness outcomes and better practices; group presentations of school/district/provincial outcomes; events based on local and regional surveillance findings; and formal conference presentations and papers. Face-to-face meetings, both formal and informal, of researchers, policy makers and practitioners consistently emerge as the most efficient way to overcome disconnections between partners. ${ }^{25}$ In addition, these KE activities take place within a larger system in which interactions occur among many partners with dynamic priorities, processes, contexts, expectations and incentives to change. Therefore, the use of numerous KE strategies that give end-users sufficient choice in content, format and delivery has been found to be important to uptake and use of evidence. ${ }^{27}$

With the increasing rates of chronic disease, it is urgent that Canada generates and uses relevant evidence to inform and guide effective interventions and healthy living policies and programs geared to youth. Research has shown that evidence-based planning enhances chronic disease prevention programs ${ }^{7,8}$ when it is used to target and evaluate programs and policies and set priorities. ${ }^{9}$ Generating data at a given time is not sufficient to evaluate chronic disease programs/policies and monitor changes in youth health. Utilizing systems thinking can bridge the gap between generating, disseminating and utilizing data. ${ }^{14}$ Systems thinking is a key tool for integrating knowledge production and use that is relevant for local action. ${ }^{14}$

\section{Limitations}

Our findings can be applied to other jurisdictions that share characteristics similar to those of Manitoba, New Brunswick and Prince Edward Island. Further research should examine the application of our findings from these three prominently rural provinces to larger, more urban jurisdictions and within complex situations. Intervention studies should explore various KE products and activities to test for their effectiveness. Also needed are more refined partnership tools and models that facilitate and support youth health KE processes. Although we have described the similarities across the three KE systems in this paper, we found differences across the three systems that we did not discuss in detail but only acknowledged in the analysis to avoid holistic bias.

\section{Conclusion}

Our findings support a KE systems approach that increases the capacity to exchange and use evidence by moving beyond simply collecting data and producing reports. Such 
systems can contribute to expanded partnership development and knowledgesharing activities, as well as the creation of comprehensive policy and practice initiatives designed to promote youth health and chronic disease prevention.

\section{Acknowledgements}

This study was funded by a financial contribution from Health Canada, through the Canadian Partnership Against Cancer. The views expressed represent the views of the authors and do not necessarily reflect the views of the project funder. The authors would also like to acknowledge Courtney Laurence, the Youth Excel CLASP partners, case study team members in each province, and all of the research participants.

\section{References}

1. World Health Organization. Preventing chronic disease: a vital investment [Internet]. Geneva (CH): World Health Organization; 2005 [cited 2012 Feb 24]. Available from: http://www.who.int/chp/chronic_disease _report/en/

2. Active Healthy Kids Canada. Don't let this be the most physical activity our kids get after school. The active healthy kids Canada 2011 report card on physical activity for children and youth [Internet]. Toronto (ON): Active Healthy Kids Canada; 2011 [cited 2012 Feb 24]. Available from: http://www.activehealthykids.ca/ReportCard /2011ReportCardOverview.aspx

3. Freeman JG, King M, Pickett W, et al. The health of Canada's young people: a mental health focus. Ottawa (ON): Public Health Agency of Canada; 2011. [Public Health Agency of Canada, Catalogue No.: 978-1100-19335-9].

4. Marshall H, Boyd R. The Chief Public Health Officer's report: report on the state of public health in Canada [Internet]. Ottawa (ON): Public Health Agency of Canada; 2008 [cited 2012 Feb 24]. [Public Health of Canada, Catalogue No.: HP2-10/ 2011E-PDF]. Available from: http://www .phac-aspc.gc.ca/cphorsphc-respcacsp/2008 /fr-rc/pdf/CPHO-Report-e.pdf
5. Health Canada. Health concerns: summary of results of the 2008-09 Youth Smoking Survey [Internet]. Ottawa (ON); [modified 2010 Aug 20; cited 2012 Feb 27]. Available from: http://www.hc-sc.gc.ca/hc-ps/tobac-tabac /research-recherche/stat/_survey-sondage _2008-2009/result-eng.php

6. Hanson M, Gluckman P. Developmental origins of noncommunicable disease: population and public health implications. Am J Clin Nutr. 2011;94(6 supplemental):1754S-8S.

7. Brownson RC, Smith CA, Jorge NE, Deprima LT, Dean CG, Cates RW. The role of datadriven planning and coalition development in preventing cardiovascular disease. Public Health Rep. 1992 Jan-Feb;107(1):32-7.

8. Alciati MH, Glanz K. Using data to plan public health programs: experience from state cancer prevention and control programs. Public Health Rep. 1996;111(2):165-72.

9. Mokdad AH, Remington PL. Measuring health behaviors in populations. Prev Chronic Dis. 2010;7(4):A75.

10. Canadian Health Services Research Foundation. Glossary of knowledge exchange terms used by CHSRF [Internet]. Ottawa (ON): CHSRF; [cited 2012 Sept 18]. Available from: http://74.81.206.232/PublicationsAndResources /ResourcesForResearchers/KEYS/GlossaryOf KnowledgeExchangeTerms.aspx

11. Graham ID, Logan J, Harrison MB, et al. Lost in knowledge translation: time for a map? J Contin Educ Health Prof. 2006; 26:13-24

12. Jacobson N, Butterill D, Goering P. Development of a framework for knowledge translation: understanding user context. J Health Serv Res Policy. 2003;8(2):94-9.

13. Canadian Institutes of Health Research. More about knowledge translation at CIHR: knowledge transfer - definition [Internet]. Ottawa (ON): CIHR; [cited 2012 Sept 19]. Available from: http://www. cihr-irsc.gc.ca/e/39033.html

14. Best A, Moor G, Holmes B, et al. Health promotion dissemination and systems thinking: towards integrative model. Am J Health Behav. 2003;27(suppl 3):S206-16.
15. Yin RK. Case study research: design and methods. 4th ed. Thousand Oaks (CA): Sage Publications; 2009.

16. Halcomb EJ, Davidson PM. Is verbatim transcription of interview data always necessary? Appl Nurs Res. 2006;19(1):38-42.

17. Miles MB, Huberman AM. Qualitative data analysis: a sourcebook of new methods. Thousand Oaks (CA): Sage Publications; 1984.

18. Riley B, Harvey D. A Manitoba Integrated Knowledge System: for the Primary Prevention of Chronic Disease [Internet]. Manitoba (MB): Partners in Planning for Healthy Living; [cited 2013 Apr 5]. Available from: http://www.healthincommon.ca/wp-content /uploads/Manitoba-Integrated-KnowledgeSystem-Feb-2006.pdf

19. Sandelowski M, Barroso J. Classifying the findings in qualitative studies. Qual Health Res. 2003 Sept;13(7):905-23.

20. Stake RE. Multiple case study analysis. New York: The Guilford Press; 2006.

21. Walter I, Nutley S, Davies H. What works to promote evidence-based practice? A crosssector review. Evid Policy. 2005;1(3): 335-64.

22. Rynes SL, Bartunek JM, Daft RL. Across the great divide: knowledge creation and transfer between practitioners and academics. Acad Manage J. 2001;44(2):340-55.

23. Jansen MW, van Oers HA, Kok G, de Vries NK. Public health: disconnections between policy, practice and research [Internet]. Health Res Policy Syst. 2010 [cited 2012 Mar 22];8(37). Available from: http:// www.health-policy-systems.com/content/8 $/ 1 / 37$

24. Wilson KM, Brady TJ, Lesesne C, on behalf of the NCCDPHP Work Group on Translation. An organizing framework for translation in public health: the knowledge to action framework. Prev Chronic Dis [Internet]. 2011 [cited 2012 Mar 22];8(2). Available from: http://www.cdc.gov/pcd /issues/2011/mar/10_0012.htm

25. Gagnon ML. Moving knowledge to action through dissemination and exchange. J Clin Epidemiol. 2011 Jan;64(1):25-31. 
26. Lomas J. Decision support: a new approach to making the best healthcare management and policy choices. Healthc Q. 2007; 10(3):16-8.

27. Dobbins M, DeCorby K, Twiddy T. A knowledge transfer strategy for public health decision makers. Worldviews Evid Based Nurs. 2004;1(2):120-8.

28. Rosenbaum P. From research to clinical practice: considerations in moving research into people's hands. Personal reflections that may be useful to others. Pediatr Rehabil. 2005;8(3):165-71.

29. Williams A, Holden B, Krebs P, et al. Knowledge translation strategies in a community-university partnership: examining local Quality of Life (QoL). Soc Indic Res. 2008;85(1):111-25.

30. Broner N, Franczak M, Dye C, McAllister W. Knowledge transfer, policymaking and community empowerment: a consensus model approach for providing public mental health and substance abuse services. Psychiatr Q. 2001;72(1):79-102.

31. Ward V, Smith S, House A, Hamer S. Exploring knowledge exchange: a useful framework for practice and policy. Soc Sci Med. 2012 Feb;74(3):297-304.

32. Kiefer L, Frank J, Di Ruggiero E, et al. Fostering evidence-based decision-making in Canada: examining the need for a Canadian population and public health evidence centre and research network. Can J Public Health. 2005; 96(3):I1-40.

33. Dobbins M, Hanna SE, Ciliska D, et al. A randomized controlled trial evaluating the impact of knowledge translation and exchange strategies. Implement Sci. 2009;4:61.

34. Lavis J, Robertson D, Woodside J, et al. How can research organizations more effectively transfer research knowledge to decision makers? Milbank Q. 2003; 81(2):221-48. 